\title{
Design of Assistive Gloves for the Blind
}

\author{
Girish Gajanaulye \\ Student, Department of MCA, Finolex Academy of Management and Technology \\ girishmulye555@gmail.com
}

\begin{abstract}
People with "blindness" are often isolated and forced to live in a limited world, as they face serious compound communication problems. This paper introduces a system to support the communication of blind and people, thus fostering their independence and integration in the society. This paper present a project idea to establish and provide ultrasonic gloves to blind people for guiding them to their right roads without the need forother people assistant. This can be done through Ultrasound waves that will be sent to the surrounding then it will be collected by detector in the gloves then to be sent Audio signalsto the blind's so they can be aware of their surroundings and they can choose their own road and way without other people assistant.
\end{abstract}

Keywords: Smart Glove, IOT, Technology, Blind, Sensors, Arduino, Project

\section{Introduction}

Suffering from blindness is not temporary for certain time it's being blindthe whole day the whole time every secondand every minutes. Once the blind person wakes up from his bed in the morning his suffering start and his daily needs start. Blind people need more care to avoid riskof injuries and that affect people around them; people need to be near for them to avoid being injured.

People around them will be exhausted from being attention to them and giving them all what they need. So Blind people must depend on themselves, this praper propose gloves which helpsBlind people to depend on themselves.Blindness can be caused by physiological dysfunction, anatomical or neurological dysfunctions. Each blind person has his own blindness type. Many scores havebeen established to assess the extent of blindness.

\section{System Plan \& Analysis}

\subsection{Existing System}

At the present, blind persons use a metallic foldable stick to walk in outside world. They walk to the road side by usingthe stick and use the black shade glasses toget identify that he is a blind person by others and keep the eyes safe from dirt or the sun.

The plan is to make them walk more freelyin the busy market and help them to reachtheir destination.

\subsection{Proposed System}

- The design of the Advance-Glove, presented in this paper, will support the blind person's involvement in the society.

- In this way, the walking freely problem of blind persons and other people is efficiently solved.

- This is achieved by using sensors like Ultrasonic sensor and buzzer that makes the work easy to blind person.

\subsection{Objective}

- Vision is important senses in the human body.
- Provided with special equipment to improve.

- Need a boost of confidence to achieve anything on their self without the needs of others.

- Blindness is not temporary for certain time.

- The main objective to make them confident and independent.

\subsection{Purpose}

- Easy to use.

- Small and light weight, so blind person can carry it comfortably.

- Provide ultrasonic gloves to blind people for guiding them on road.

- Helps Blind people to depend on themselves.

\subsection{Software/ Hardware Requirement}

Any system, application or device requires some of available equipment to work efficiently and properly, so that this system requires selection equipment and taken into consideration that every part, which will provide to the system must be an occasion for the service to be useful and activity for the meant category.

System contains several tools including:-

\section{- Ultrasonic sensor}

The HC-SR04 Ultrasonic (US) sensor is a 4 pin module, whose pin names are VCC, Trigger, Echo and Ground respectively. This sensor is a very popular sensor used in many applications where measuring distance or sensing objects are required.

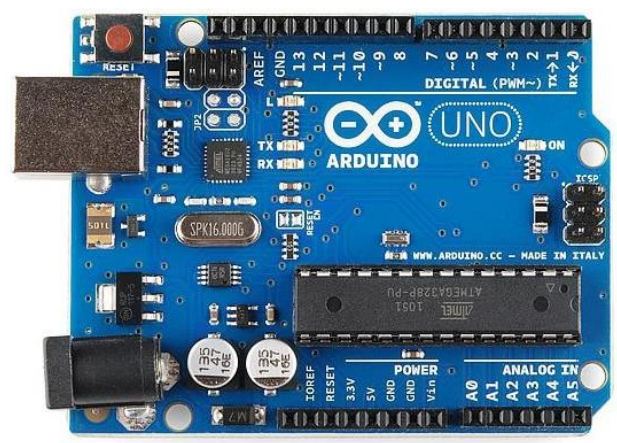




\section{- Jumping wires}

Jumper wires are used for making connections between items on your breadboard and your Arduino's header pins. Use them to wire up all your circuits.

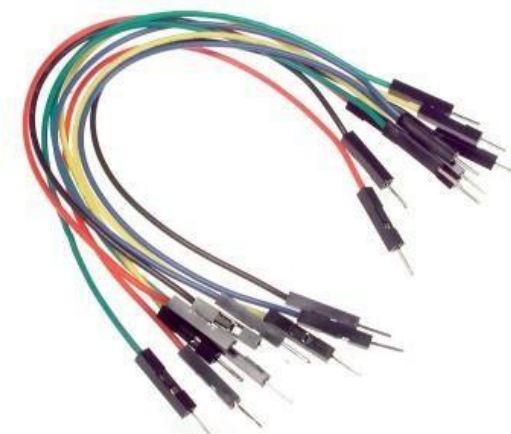

\section{- 9v Battery}

The nine-volt battery, or 9-volt battery, is a common size of battery that was introduced for the early transistor radios. It has a rectangular prism shape with rounded edges and a polarized snap connector at the top. This type is commonly used in smoke detectors, gas detectors, clocks, walkietalkies, electric guitars andeffects units.
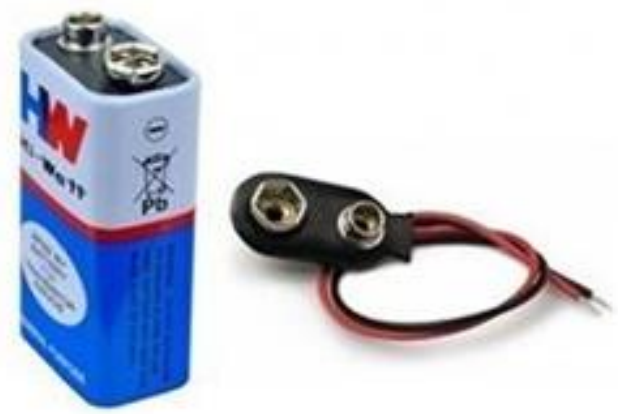

Software: - Arduino IDE 1.8.13 Language: - C++ Programing language

\section{Photo}

\section{System Design}

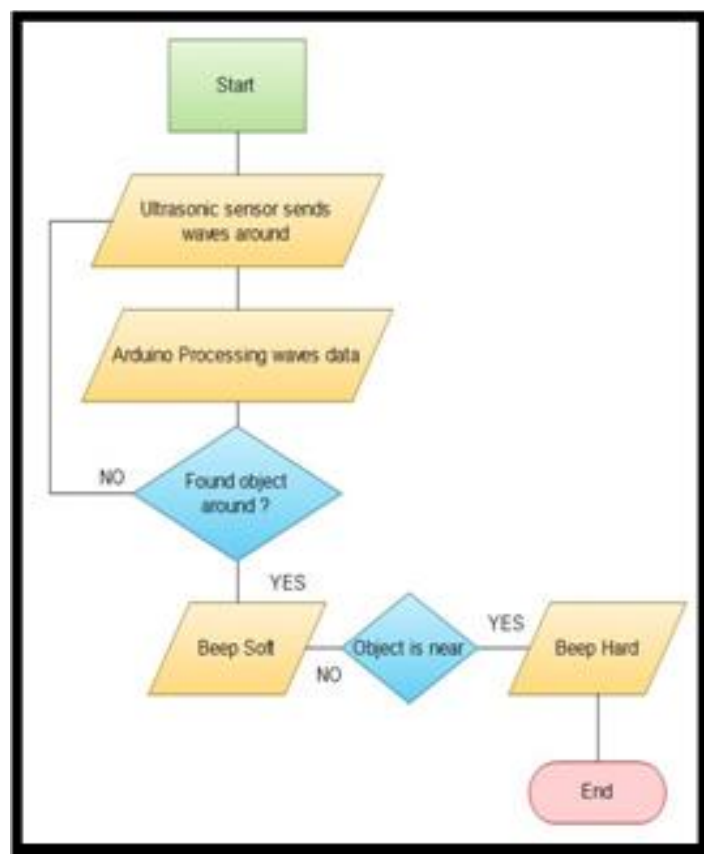

\section{Advance Gloves for blind Circuit Diagram}
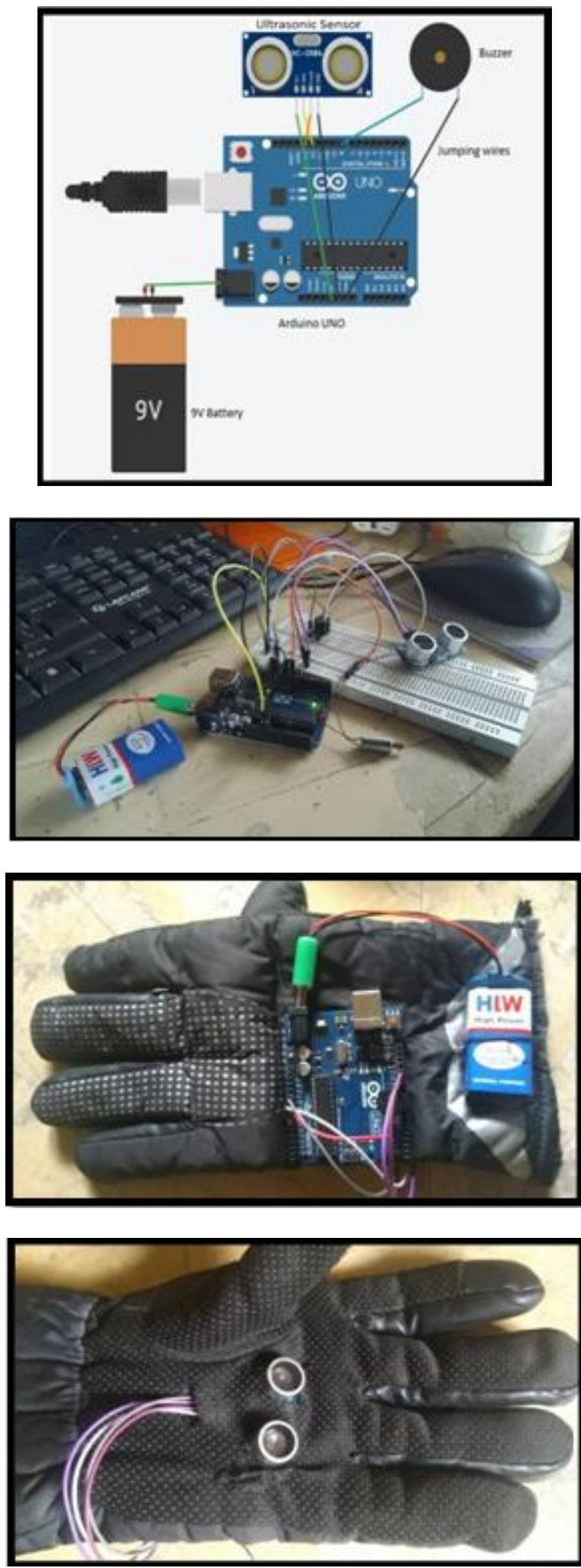


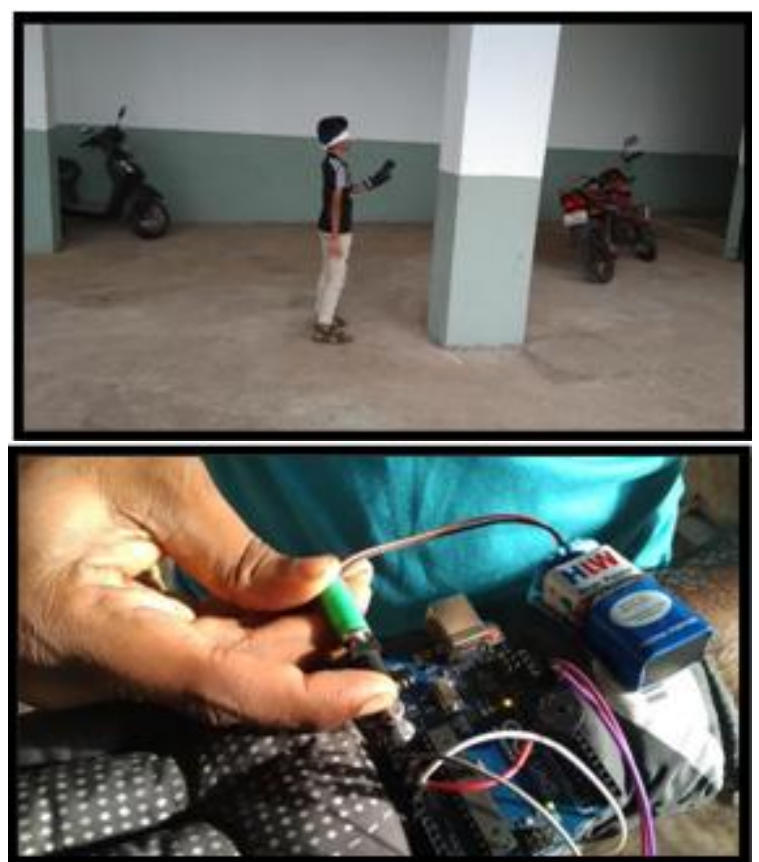

\section{Methodology}

The project consists of left gloves worn bythe user. To begin the gloves activity user need to direct his hand to know if there was handicap objects around through beepfrom gloves. Gloves alarm when any object is on its side. In addition, it alarm when any object is in front of the user.

Ultrasonic sensor works as input device which sends data of objects around to arduino microcontroller for processing and sentencing which respond should give Arduino command to buzzer, which work as output device to respond through, givesbeep alarm.

The proposed device is divided into twomain parts:

- Ultrasonic sensor (input device)

- Buzzer(output device)

Ultrasonic sensor exports inputs data about objects distance around it to a Arduino to process this data then commanding buzzer to give output in formof beep in accordance with programming of Arduino. Arduino will give buzzer orderto alarm with continuous beep when the object is close from the user. When the object keep away "few" from the user, the Arduino will give buzzer order to alarm with intermittent beep. When the object keep away "more" from the user, the

Arduino will order a buzzer to give no beep. Ultrasonic will back to send waves to find objects. Then repeat the process. Many experiments dedicated to blind gloves was conducted to know the qualityof performance expected of them.

Here the threshold is set set differently to the height of the person. I have converted the units coming from the ultrasonic sensor into centimeters. Using this centimeters it became use to set the threshold and give beep after a some distance.

Let's consider the height of the blind person is 5 ' 2" which is average height of any Indian person then feet then thresholdwill be set as:-

First convert the ultrasonic sensor units into centimeters by cm $=($ us_units $* 0.0034) / 2$

Let $\mathrm{x}$ bet the height of person $x=5$ '2'.

And here we are converting this inches intocentimeters where 1 inch $=30 \mathrm{~cm}$.

Then threshold will be calculated as

Threshold $=(x / 2) * 30$

Here we get threshold considering theaverage height of an Indian person as

Threshold $=(x / 2) * 30$

$=(5.2 / 2) * 30$

$=78 \mathrm{~cm}$

So we can set the threshold of $78 \mathrm{~cm}$ or inrange of $75-80$ $\mathrm{cm}$.

\section{Future Scope}

This system would be more setups sophisticated and assistant for the visually impaired around the world, and so high for his efficiency. In addition to the low-cost of manufacture it, and according to the accuracy of the sensor. In spite of this, it is recommended to restructure the pieces added or commercial quality to its requirements to lead properly. In the future, some improvements will be improved to the system in order to meet approbation of users such as:

- Increasing other type of sensors as pulseand temperature sensors.

- Increasing navigation system and an internal memory to store all places by the user

- Adding automatic synchronization between the gloves and mobile phones to be identified on the site by a person other relatives or theirs.

- Adding voice guidance property to makeit easier to stay away from the process of risk if the beep were unavailing.

\section{Conclusion}

This paper proposed Advance glove for blind people using Arduino. That it is a solution for the visually impaired and those who do not wish to carry on his stick. The blind person will be able to move fromside to side and from one place to another without the need to help others to learn about the highs and surrounding objects.

\section{References}

[1] "Arduino Architecture" https://www.engineersgarage.com

[2] "Sensors" https://tkkrlab.nl/wiki/Arduino_37_sensors

[3] "Ultrasonic glove for blind anddeaf people" https://www.irjet.net/archives/V4/i12/IRJETV4I12190.pdf https://www.scirp.org/journal/ 
paperinformation.aspx ?paperid $=94266$

[4] "Smart Glove for visually impaired" https://www.google.com/searc

$\mathrm{h}$ ?sxsrf=ALeKk01ZeHKz8E9

Jwlzxez8NP270GKYxeQ:162

$6268260835 \& \mathrm{q}=$ smart+glove

+ for + blind \&spell $=1 \&$ sa $=X \& v$

ed=2ahUKEwjxh_yv0eLxAh

VdwTgGHQndCD0QBSgAegQIARAw

[5] VijayMadisetti and ArshdeepBahga, "Internet of Things (A Handson- Approach)", 1st Edition, VPT, 2014.

[8] Hakima Chaouchi, The Internet ofThings: Connecting Objects Francis DaCosta, "Rethinking the Internet of Things: A Scalable Approach to Connecting Everything", 1st Edition, Apress Publications, 2013. 